\title{
The Client
}

\author{
LIANE HANCOCK \\ University of Louisiana at Lafayette
}

\section{DAN BURKETT}

University of Louisiana at Lafayette

As a teaching profession, faculty need not only to accommodate, but also to embrace differences in an increasingly diverse client base. Faculty need to move beyond empathy and doing good to respect and service. To facilitate this, students need to have real clients introduced at an earlier stage - down at foundation level. This paper serves as case study: it outlines changes to assignments in second year studio that enhance student engagement, and traces results through student interview. The paper describes the direct experience in the foundation studio, and documents how that experience affected students' view of client.

\section{INTRODUCTION}

Within the last several years, the collateral organizations of architecture have increasingly focused on diversity and inclusion, both in terms of the students served and professional practice. However, with few exceptions, the dated methods by which faculty pedagogically approach diverse and inclusive interactions largely remain the same. Too often, the studio project prompt perpetuates the "master-student" mindset into an "architect-client" relationship to create the same top down, master based approach that academies now question. From stakeholders within the community to a broader distributed network of users tied together by specificity in area of need or service, the profession and academia must accept that clients are sophisticated in their desires and goals. As a teaching profession, faculty need not only to accommodate, but also to embrace differences in an increasingly diverse client base. Faculty need to move beyond empathy and doing good to respect and service.

Real clients need introduction at an earlier stage - down at foundation level. Using abstracted clients in beginning design is simply an out of date method: designing something like a home for an artist or a collector serves only a tiny slice of the populace and does not address students' thirst for agency within their community. By designing for someone specific, students learn to both incorporate and filter minutiae to align with innovative design solutions. This learning outcome obviates the pervasive concern that communication with clients too quickly lands in the weeds and distracts from broader design strategies delivered in foundation coursework. Instead, students learn to translate clients' aspirations into qualitative, programmatic, formal, and organizational decision making during design
KARI SMITH

University of Louisiana at Lafayette process. Fundamental to success is the timing and way in which the studio introduces clients, and the specific assignments that engage in productive interaction between client and student.

This paper serves as case study: it outlines changes to assignments in second year studio that enhance student engagement, and traces results through student interview. The information presented is from a studio run successively over a two-year period. The studio utilized the same programmatic organization, the same site, and the same design process, but significantly altered the list of clients and the methods by which the students interacted with those clients. In lieu of clients foreign to the area, we drew upon locals who were directly accessible through interview. An additional change included diverging from a selection of clients that were of European descent, Caucasian, male, middle aged and able bodied to a range of race/ethnicity, sexual orientation, gender identity, age, and physical and learning abilities , which more closely mirror both our student body and the general populace. The paper describes the direct experience in the foundation studio, and documents how that experience affected students' view of client

\section{INTRODUCING THE CLIENT}

The second year studios at University of Louisiana Lafayette have a long tradition of studying phenomena within the natural environment, teaching students to poetically frame that phenomena through material and tectonic investigation. Across our school, studios emphasize locus - place, environment, and culture. Our university is located in the heart of Acadiana, the Francophone center of Creole and Cajun culture, and being adjacent to the nation's largest wetland and swamp, the Atchafalaya River Basin, our program values wetland ecology and culture. To this end, we located the second-year spring project in this landscape. The culture is rooted in local cuisine, traditional music, sportsmanship, and an emphasis on multigenerational celebration.

In my research, I have been studying the dichotomous relationship between man-made and natural ordering systems in the Atchafalaya Basin, and their effects on the landscape over time. At multiple scales, cyclical patterns of growth and decay affect the human perception of time and place. -Adam Ortego, 2nd Year Student 
I would like to create a retreat for you and your students. A place away from the bustle of city life, that allows mental freedom. A place where all things negative become beautiful through spoken word. Nature serves as a remedy for all ailments. -Tyree Barnes, 2nd Year Student

The student body is diverse in its race/ethnic and gender makeup. The second year demographics in 2018 were $50 \%$ female, 20\% African American, and another 15\% non-white. In previous years, selection focused upon nationally recognized authors, artists, and craftsmen, seeking to substantiate the importance of issues like craft and narrative, which were an overall themes of the studio. However, those world-famous people were fundamentally inaccessible, creating a layer of abstraction that limited students' interpersonal connection.

To select clients this past year, we chose people who were both representative of our student population, and the culture of the area. Taking the new tact of focusing upon local citizens, we found a more organic and deeper connection occurred as the students completed research and interviewed the clients directly. Leaving artifice behind, the students were given the tools, information, and access to value the client authentically.

\section{PROJECT PROMPT - CLIENT PROFILES:}

- Alex "PoeticSoul" Johnson, recent university graduate, spoken word artist and social activist, African American

- Anya Burgess, violin maker, restorer, and player

- Melissa Darden, basket maker, Native American

- Brian Guidry, painter of landscapes

- David Joseph Theriot, octogenarian, fisherman, former Army Corps employee

- Faren Serrette, boat builder

- Toby Rodriguez, chef and proponent of boucherie

I cannot begin to express how utterly excited I am to be working with you in the near future. Your basket weaving is mesmerizingly beautiful, both in methodology and aesthetics, and sparks inspiration in every way possible. -Jacqueline Switzer, 2nd Year Student

\section{THE LETTER TO THE CLIENT}

The introduction to the client occurs roughly a third of the way into the semester. Students begin the semester by selecting and analyzing one of five sites within the Atchafalaya Basin, developing drawings and models that describe systems acting upon the site. As faculty, we use the introduction of the client to provide transition from site analysis to design. The students are tasked with researching the client list and selecting one, to whom the students must write a letter. Resources for research include websites, videos, published articles, and direct interview.
From the protohistoric Chitimacha tribe to our current commercial and personal presence in the basin, Atchafalaya natives have reaped the blessings the river has to offer... Your conscious, careful interaction with the basin has provided you and your family a way of life... I am confident that I can design architecture that will restore a sense of responsibility in usage, re-emphasizing the natural, hierarchical bond between mankind and the Atchafalaya. - Stephen Corcoran, 2nd Year Student

Our school has adopted a Writing Across the Curriculum Program. Supporting this curricular thread, second year spring semester studio has two writing assignments: a reading/response within typical canon, and the aforementioned "letter to the client."

Previous to last year, the client letter was assigned through a prompt introducing a wide range of source material. The assignment asked students to describe their concept and how it translated into tectonic investigation and site selection, how site influenced design, and also required a description of the ways in which passive heating and cooling systems, materials, and structural systems would be used. The assignment asked for a logical thread throughout, and provided reference to a number of noted critical regionalist architects, to help focus outcome. In hindsight, while assigned in earnest, the letter had little or nothing to do with the client. Nor did it explore the student's voice, or give them agency to truly be creative. While nodding to the importance of the client, the letter was really a structure by which to get students to describe their intentions, and to do superficial research on subjects that were deemed important to studio.

As we re-envisioned the list of clients, we also realized we needed to re-envision the scope of the client letter. In lieu of a laundry list of expectations, we drastically reduced the requirements. We simply asked the students to write a heartfelt narrative on why the site they had chosen would be perfect for their client.

Through my studies of the site, I have found that during each season, the sunlight's intensity is altered. Spoken word and sunlight are one in the same. -Tyree Barnes, 2nd Year Student

Though the Basin has suffered over man's control, there is beauty present in small and large scales. The hyacinth, though overpopulated, brightens the winter landscape with a rich, green horizon line. -Emilie Hebert, 2nd Year Student

\section{PROJECT PROMPT:}

First, select a client from the list provided and conduct research to learn more about their craft/practice/profession and disposition. Next, compose a letter to your client that brings together your site understandings and the opportunities that you believe are physically and latently present in the site that will make for an exciting project particular to your client. 
Taking this new tact, the assignment then simply discusses good writing traits, emphasizing effectiveness: ideas and content focusing upon relevant supporting detail; logical, creative, and effective organization; expressive, enthusiastic, and sincere voice; precise and vivid word choice; well-crafted yet varied sentence patterns; and control of standard conventions. These writing traits are based on The Six Traits Writing Rubric Adapted for Regina Public Schools, a rubric that we refer to for all of our writing assignments across our school. (1)

I am grateful to work with you to create a haven for creatives like yourself and your mentees. I am certain that the site will meet your expectations and provide adequate refuge for the creative community of Lafayette. - LaShayla Lumpkins, 2nd Year Student

I see the oxbow lake as coming from such a powerful source (given the Atchafalaya drains much of this continent), but then turning into this gentle body of water. I sense that this could be a strong relationship to what you do. The general idea of a pig being slaughtered seems gruesome but in honesty, it becomes an art form to witness a boucherie. It feels like a harmonious event... -Jade Honegger, 2nd Year Student

\section{HOW STUDENTS LOOK BACK UPON THIS EXPERIENCE}

One semester later the students from last year shared their thoughts with us regarding the importance of this assignment. In their current studio they have been asked to construct a detailed biography of a client that they invent; several feel that their experience in the spring semester gave them a structure by which to develop their new client.

In Arch 202, there wouldn't have been a project without the client, which is true of architecture in the real world... I had to dive deep, and learn about my client's job as well as what she enjoyed in her free time, in order to design a space that could be functional for a multitude of needs. Every wall and every window was representative of my clients personality, and how I imagined she would benefit from the space. Based on the success I had with learning about my client in 202, I was able to select a client in Arch 301 with enough layers to help me dictate a design for a multi-functional space that will be representative of the fiery personality that my client possesses. In the design process, my client's personality helps influence the way that I began to gesture a design for my building. Selecting a client helped inform me on what my space needs, and how I need to adapt the space so that the architecture can speak on behalf of my client, while simultaneously providing a service to my client in a way that enhances her own business. -Ananise Hulin, 2nd Year Student

I believe the client letter from arch 202 allowed me to begin to understand what it means to design for someone other than myself. Being able to speak to my client and ask them questions about their self and their vision for an optimal teaching space was a great foundation for having to imagine a client in my third year studio. Now, I have a better sense of what clients will potentially look for in the design and what best suits their needs and expectations. -LaShayla Lumpkins, 2nd Year Student

Several provided broader answers:

The most insightful thing that I learned from this project is how essential it is to keep your client and human experience at the forefront. I think it's hard for aspiring architects to remember that at the core of what we do is creating a space for people to inhabit. As students, it's sometimes easier for us to keep our concept and design as the most important aspect. It was enlightening to be able to have an actual being to design a space for. It brought everything into perspective. - Madeline Higginbotham, 2nd Year Student

While writing my client letter, I was thinking of how to create a conducive invitation to the project I had in mind... Spoken word is something that is influenced by environmental factors, and I had used that to advantage to tailor a letter that would reinforce the site of choice through the comparison of spoken word and the seasons. The letter helped with the advancement of my project by adding reasoning to my phenomenological studies. The final design is a culmination of these ideas. -Tyree Barnes, 2nd Year Student

The lead faculty member in the third year studio has found a positive change amongst the students. In third year, students are asked to write the narrative for their clients, effectively inventing their story. Mr. Gjertson states that he has found this year's students' narratives present clients with more multi-layered personalities, which are often more fanciful, with a clear dark and good side. Additionally the students began the semester with a short design project for a farmer's market, a project that had a real client. Mr. Gjertson found the students were very mature, professional, and polite. They approached the client with respect and modesty. While he said he would expect our student's in general to behave this way, he did take note that this year, the first that introduced a real client in this short kickoff project, he was very pleased with how carefully they listened to the client.

\section{CONCLUSION}

Introduction of members of the community as clients for our second-year spring studio drastically changed the way in which students engaged with their projects. It provided the students with a direct personal connection, and in turn they connected with the specificity of the project with optimism and unbridled energy. The students fundamentally felt they had agency, and with that agency they could explore their design voice in service to others. Most rewardingly, it seems this exercise has resonated with the students, influencing how they expect to engage the client both currently, and in the future. 


\section{ENDNOTES}

1. Spandrel, Vicki.The Six Traits Writing Rubric Adapted for Regina Public Schools

from Vicki Spandel, Creating Writers. Regina, SK Canada. https://artsedge.

kennedy-center.org/ /media/ArtsEdge/LessonPrintables/grade-6-8/

writing_a_fable_six_traits_writing_rubric.ashx 